ojs.uv.es/index.php/qdfed

Rebut: 28.06.202I. Acceptat: 20.07.21

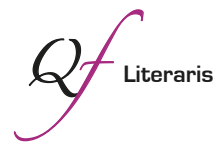

Per a citar aquest article: Naval, María Ángeles. 202I. "Estirpe de perpetradores (pequeñas mujeres rojas de Marta Sanz, novela negra de la memoria histórica)". Quaderns de Filologia: Estudis Literaris XXVI: 39-60.

doi: $10.7203 /$ qdfed.26.22097

\title{
Estirpe de perpetradores (pequeñas mujeres rojas de Marta Sanz, novela negra de la memoria histórica)
}

\author{
Perpetrator's Lineage (pequeñas mujeres rojas by Marta Sanz, Noir Novel \\ of Historical Memory)
}

\author{
MARÍA ÁngEles NAVAL \\ Universidad de Zaragoza \\ manaval@unizar.es
}

\begin{abstract}
Resumen: pequeñas mujeres rojas de Marta Sanz es una novela de la memoria histórica, comprometida con la construcción de la memoria democrática española, que se centra en la figura del perpetrador Jesús Beato - un delator- y su estirpe. El móvil de Beato es la codicia. Sus descendientes heredan los bienes logrados con el crimen y también la condición codiciosa y criminal. En cuanto que novela de la memoria, se inscribe en el giro victimario y busca una relación clara y unívoca con el pasado, con las exhumaciones de fosas y su significado histórico. Las marcas de novela negra otorgan centralidad al corpus delicti, al cuerpo lacerado y asesinado de Paula Quiñones, que se convierte en testimonio de la perpetuación de la violencia en la historia reciente de España (I936-20I2). Esta novela negra de significado histórico se proyecta sobre el cine y la literatura fantástica y de terror como forma de representar el mal y de corregir la banalidad del mal.
\end{abstract}

Palabras clave: novela española contemporánea; Marta Sanz; novela de la memoria histórica; novela negra; giro victimario.

\begin{abstract}
Marta Sanz is a historical memory novel engaged with the construction of the Spanish democratic memory. It focuses on the figure of the perpetrator Jesús Beato (an informer) and his relatives. Beato's motivation is greed. Their descendants inherit the assets gained from the crime as well as the greedy and criminal condition. As a novel of memory, it takes part of the perpetrator's turn of cultural representations and it seeks a clear and univocal relationship with the past, with the exhumations of graves and their historical significance. The literary features of the crime novel give centrality to the corpus delicti, the lacerated corpse of Paula Quiñones, which becomes a testimony to the perpetuation of violence within the recent Spanish history (I936-20I2). As a hypotext, this crime novel has some horror films and tales. Horror is the way of representing evil and correcting the banality of evil.
\end{abstract}

Keywords: Spanish contemporary fiction; Marta Sanz; historical memory novel; crime novel; perpetrator's turn. 


\section{Paula, pequeña; pequeñas mujeres rojas}

Las pequeñas mujeres rojas aparecen representadas -metaforizadas, metonimizadas por el color- en las pequeñas amapolas de la cubierta del libro de Anagrama $^{\mathrm{I}}$ Las amapolas son mujeres pequeñas y son además las flores de la memoria de los muertos en la guerra. Moina Michael leyó los versos del lugarteniente canadiense McCrae sobre los soldados americanos muertos en la Primera Guerra Mundial en Europa: "Se agitan las amapolas en los campos de Flandes/ entre las cruces”. Tras leer estos versos, según relata Daniel Schönpflug (2020: IO-II), Moina decidió convertir la amapola en la flor de la memoria de los muertos: "ella debe encargarse de que el recuerdo de miles de víctimas no se pierda, de que su muerte no haya sido en vano y de que su muerte tenga un sentido". El deber de memoria o el impulso generoso por tener memoria late espléndidamente en las páginas de la novela que nos ocupa.

pequeñas mujeres rojas (2020) es la tercera entrega de la saga de novelas detectivescas -negras, policiacas- escritas por Marta Sanz entre 20I0 (fecha de publicación de Black, black, black) y 2020. En 2012 apareció Un buen detective no se casa jamás. Es probable que la serie concluya en trilogía porque en la última novela muere Paula, protagonista in praesentia o in absentia de las tres novelas. La acción de Un buen detective no se casa jamás es simultánea a la de mujeres rojas: el verano de 20I2. La muerte de Paula, el sacrificio del personaje perpetrado como crimen abyecto, es una decisión clave de la autora y, como se verá quizá en las siguientes páginas, dimensiona lo que hay en esta novela de tesis comprometida con: la defensa de las reclamaciones de los familiares de víctimas de la Guerra Civil y de la represión franquista; con la construcción de una memoria democrática del pasado español del siglo xx; y con la justa restitución de la épica de los vencidos y las vencidas. El libro subraya la existencia de fusiladas en las fosas y de represaliadas. Ese relato no requeriría la muerte de Paula, la voluntaria que acude al pueblo de Azafrán para ayudar en la exhumación de los cadáveres que yacen amontonados en una fosa común desde la Guerra Civil, desde el verano de I936. Marta Sanz ha sacrificado a su pequeña Paula, la coja guapa que se parece a la actriz Soledad Miranda ${ }^{2}$, la lis-

\footnotetext{
I Todas las citas del texto de pequeñas mujeres rojas irán referidas a esta edición de 2020 y se consignará exclusivamente el número de página entre paréntesis junto a la cita.

${ }^{2}$ Según hace saber la propia autora, se refiere a la Soledad Miranda que apareció en películas de Jess Franco a principios de los setenta.
} 
ta y calculadora inspectora de Hacienda, para convertirla en una amapola de la memoria, en garante de que la muerte de las víctimas no haya sido en vano.

La memoria histórica y la justa reparación de las víctimas se teje en esta novela con la reflexión sobre el mal, sobre el dolor y sobre las formas de representación literaria y cinematográfica -las formas de narrar- de la violencia. pequeñas mujeres rojas novela la violencia, la brutalidad y sus causas y consecuencias morales. Es una novela policiaca en la que se reconstruye un doble crimen: Paula comienza a investigar detectivescamente, mediante pruebas (el siniestro cuaderno), evidencias caligráficas y de cómputo de desaparecidos, la existencia de otros muertos de la guerra que deberían hallarse en el entorno de Azafrán y no se encuentran en la fosa que está siendo excavada. Paula será asesinada por acercarse demasiado al descubrimiento de esa fosa y al señalamiento de los responsables y usufructuarios de su existencia. Porque un tema clave es la existencia de beneficiarios en 2012 del crimen de I936 y con ellos de la envidia cainita y de la codicia. Luz Arranz reconstruye los hechos en torno al asesinato de Paula y sus consecuencias. Lo que leemos en la novela son las cartas escritas por Paula a Luz Arranz mientras investiga los crímenes de las fosas y la reconstrucción del asesinato de Paula por Luz Arranz. Las tres partes del relato van precedidas y clausuradas por sendos parlamentos del coro de voces de las víctimas asesinadas en I936. Otros dos parlamentos del coro hacen de interludio entre las partes. El asesinato de Paula urdido por Sanz subraya la violencia del crimen -el de Paula y los de la guerra- ejercida sobre los cuerpos -cada uno de los cuerpos-arrojados, transformados en objetos abyectos por el crimen y las causas del crimen.

pequeñas mujeres rojas sigue siendo una novela negra, aunque en explosión, podríamos decir: se presenta formando serie con las mencionadas entregas y comparte con ellas personajes que ejercen tareas detectivescas: Paula, Luz y Zarco ${ }^{3}$. Como tal novela negra, se escribe para contar un crimen, el de la pequeña Paula que investigaba los crímenes de la Guerra Civil. El cuerpo

\footnotetext{
${ }^{3}$ Las novelas negras de Marta Sanz responden de manera sui generis a las marcas del género negro o policial. La transgresión más evidente de estas marcas es la falta de operatividad del personaje detective, Zarco: homosexual enamoradizo que estuvo casado con Paula a la que ha dejado una cojera sentimental notable. Zarco se enamora de Olmo, hijo de Luz Arranz. Luz Arranz es una mujer sola, madura y menopáusica, cuya complexión recuerda a la de Simone Signoret y que escribe por recomendación de su terapeuta. Paula y Luz hacen croquetas y son las que desentrañan los crímenes en los que se ve envuelto Zarco. Luz Arranz es una magnífica escritora. Su imaginación bastante gore parece hacer las delicias de la verdadera autora, Marta Sanz.
} 
del delito, el cadáver de Paula, solo si no leemos atentamente, puede considerarse un daño colateral de la historia principal (la Historia), relacionada con la exhumación y con la aplazada justicia transicional ${ }^{4}$. El asesinato de Paula no se produce al comienzo de la novela. El arranque de la investigación policiaca está diferido. Sanz maneja el suspense. La reconstrucción del asesinato de Paula exige remontarse primero a los crímenes cometidos por los falangistas en Azafrán durante el verano de 1936 y por el delator Jesús Beato, verdadero bigbang de una sucesión de crímenes y abyecciones en expansión constante. Los crímenes del verano de 1936 no quedan clausurados con la muerte del abuelito Jesús (Jesús Beato, el delator) ni con el encarcelamiento de quienes purgan en presidio o en manicomio la muerte de Paula, ni con la exhumación de la fosa sobre la cual la dinastía de los Beato había edificado su enferma y maléfica prosperidad familiar. Hay herederos que no están entre rejas: estirpe de perpetradores.

\section{Rojo y negro: Negro profundo, cosecha roja}

La presencia titular del adjetivo "roja" en plural, "rojas", establece un nexo deliberado entre esta novela y uno de los clásicos del género negro, Cosecha roja (Red Harvest, I929) de Dashiell Hammett. La deliberación se corrobora por la acumulación de indicios. Paula tiene un defecto físico como el Agente de la Continental. El contexto del conflicto minero (rojo) y el número de cadáveres de Cosecha roja hace simetría con la lucha obrera en la España de I936 y el amontonamiento de cadáveres en pequeñas mujeres rojas. El papel de los poderosos y la continuidad entre padres e hijos poderosos son significativos en ambos textos. El juego de palabras venenoso en el nombre de los lugares en los que se cometen los crímenes también es operativo en los dos textos: en la novela americana del año veintinueve Personville es Poisonville y en la española del año veinte (casi un siglo después) Azafrán se transforma en Azufrón

\footnotetext{
${ }^{4}$ Como ocurre con una buena parte de la narrativa de la memoria histórica española del siglo xxi la Transición es un punto de referencia. Dentro de la cronología interna de la novela I975 es el año en que nace David Beato, el heredero del abuelo Jesús, el fruto perdurable del ayuntamiento o coyunda de las sangres (malas sangres) del barbero y el peón caminero, delator y cómplice de los verdugos falangistas respectivamente. La fecha de I975 es la escogida para marcar en el tiempo la continuidad impune de los crímenes de la guerra y del franquismo. La reflexión sobre la Transición ha ocupado a la autora de Daniela Ástor y la caja negra y de Éramos mujeres jóvenes. Una educación sentimental de la Transición española. Sobre la Transición en Marta Sanz véase Violeta Ros Ferrer (2014, 2020) y también Alex Matas Pons (202I).
} 
(el diablo huele a azufre, como se sabe). La relación hipotextual con Cosecha roja genera una superposición de capas de tiempo histórico, de momentos de combate y cosecha rojos en la historia.

Paula Quiñones acude como voluntaria a la fosa de Azafrán, alentada por la memoria de la Guerra Civil que ha heredado de su abuelo. Es una representante de "la memoria de los nietos de la guerra civil" (Paloma Aguilar Fernández y Leigh A. Payne, 20I8: 30) porque así lo ha querido su autora de manera muy deliberada'. El coro de "los niños perdidos y las mujeres muertas" nos informa:

Sabemos que los recuerdos de Paula no pertenecen a este lugar ¿Por qué llega entonces a este pueblucho a ocuparse de las tareas sucias, desenterrar huesos muertos (...) reavivar los odios de una fogata (...) ¿Por qué quiere ponerles nombre a los despojos? (p. I3) [...]

Paula Quiñones, nieta de Manuel, compañero superviviente de acribillado fé$\operatorname{mur}(\ldots)$

Cada frase de Manuel se le quedó dentro, sin que ella se diese cuenta, y la transformó en una coja idealista y acaso filantrópica. Todo lo que sabe Paula lo sabe por boca ajena (p. I7)

El coro fatídico nos advierte en el arranque de la novela de que Paula se dirige hacia el lugar que no debe, la casa hotel de los Beato, y de que las voces van a intentar cuidarla, aunque su ayuda no servirá de mucho "cuando lleguen los peligros" (22).

La novela señala que la actividad memorial de Paula es una actividad peligrosa. Escribe Luz Arranz a Zarco:

Quizá Paula me escribía estas sentencias, indelebles sobre la cuadrícula de sus cartas, porque su trabajo entrañaba peligro. Y mientras pasaban los días [...] los peligros se hacían más acuciantes (92-93).

\footnotetext{
${ }^{5}$ Rosa, la compañera de trabajo de Paula en la fosa de Azafrán, también tiene el punto de vista de los "nietos de la guerra civil". Se trata de un dato histórico contextual, ya que, como señalan Aguilar y Payne (20I8), ha sido la llegada de esta nueva generación más combativa y sin el miedo de sus padres la que está reclamando la emergencia del pasado violento español relacionado con la represión franquista durante la guerra y la posguerra. "Esa era la imagen que Rosa llevaba buscando (...) Lo importante no era su abuelo, aunque fuera importantísimo, lo importante eran los abuelos de todo un país y los hijos de los hijos de los abuelos de todo un país" (80).
} 
Que el trabajo de exhumación de fosas de la Guerra Civil entrañe peligro no es una cuestión que ataña exclusivamente al suspense de la trama, además, se proyecta sobre el presente de la escritura, 2020: unos proponen la coexistencia contenciosa de las memorias de la violencia de la guerra y otros emborronan los monolitos y disparan contra los lugares de memoria de los vencidos, como se señalará en el capítulo final de novela, "Monolito Blues". La exhumación de las fosas del silencio es una actividad peligrosa dentro y fuera de la novela.

No es infrecuente en la narrativa reciente encontrar referencias a la actividad de exhumación de fosas como una actividad frívola e interesada, realizada al amparo de facilidades y subvenciones generadas por la Ley de Memoria Histórica y la conveniencia del momento político (Marías, Trapiello, incluso Juan Marsé ofrecen testimonios al respecto; la novela de Javier Cercas sobre el caso histórico de Enric Marco apunta en esta línea) (Naval, 20I9). La negra trama novelesca de Marta Sanz quiere poner de manifiesto todo lo contrario. El trabajo voluntario de exhumación de cadáveres de las fosas comunes del franquismo es un activismo complicado y muy peligroso. Ese peligro que evidencia la trama criminal de la novela se corrobora con los hechos históricos de vandalismo de que han sido objeto los monumentos conmemorativos de las fosas comunes, que han obligado a optar por el abstracto monolito para evitar que a los fusilados conmemorados se les fusilara de nuevo en efigie, como ocurrió en el Mirador de la Memoria (Cáceres) y refiere la autora en el capítulo titulado "Monolito Blues. Lea despacio" (33I).

La negra y fabulosa novela de Sanz se inscribe en un tipo de narrativa de la memoria que quiere mantener una relación sólida, factual y nítida con la historia $^{6}$. De ahí la verosimilitud de los personajes cuyas voces hablan desde la fosa o desde las urnas que contienen los restos exhumados: el maestro,

\footnotetext{
${ }^{6}$ Ya se ha comentado la deliberación con la que Paula se presenta como una nieta de la Guerra Civil, que ha heredado la memoria comunicativa de la guerra a través de su abuelo. Dieter Ingnrschay-Janett Reinstädler (20II) y Ulrich Winter (2010, 2018) han establecido unos momentos y/o tendencias en la evolución de la que estos autores alemanes llaman escritura postdictatorial, pero que quizá acabe denominándose escritura transicional. Ulrich Winter acuña el término "memoria performativa" para referirse al giro que los escritos -así como la cultura y otras manifestaciones sociales- relacionados con la memoria histórica muestran en este siglo xxI. Estos escritos estarían marcados por la necesidad de hacer presente, ontologizar, presentizar el objeto de memoria. Sin duda, esta novela de Marta Sanz, pese a que se aproxima a los géneros fantásticos en su representación del mal, busca esa materialidad y evidencia documental y fehaciente en el peso del cuerpo de Paula asesinado en la ficción y el peso de los restos corporales de las víctimas históricas a los que la ficción dota de cuerpo.
} 
el homosexual, el brigadista y la histórica y documentada mujer que llevaba encima el sonajero de su bebé cuando fue fusilada. El perfil biográfico de los personajes enterrados en la fosa de Azafrán constituye un recurso para anclar la ficción novelesca en la historia de España. El personaje de la madre enterrada en la fosa conserva el nombre -Catalina- de la figura histórica en la que se inspira y a la que rinde homenaje: Catalina Muñoz Arranz, la madre del sonajero de la fosa de Cevico de la Torre ${ }^{7}$. Esta mujer asesinada en septiembre de I936, conmemorada y rehabilitada en pequeñas mujeres rojas, comparte su segundo apellido con el de la narradora intradiegética, Luz Arranz, quien a su vez lo comparte con la abuela de la verdadera autora, Juanita Arranz. Todas son pequeñas mujeres rojas reales o de ficción y tejen la novela sobre el cañamazo de la historia de España, las historias de las familias españolas y las historias personales de la familia de la verdadera autora Marta Sanz Pastor Arranz:

Mi abuela Juanita, pequeña mujer roja, uno cincuenta y dos, conciliadora, cuidadora, obrera en una fábrica de perfumes, hija del pescadero Benedicto Arranz, que enseñaba a leer a quien no sabía con las páginas de El Socialista y sufrió prisión en Cuéllar... Mi abuela Juanita, que se ha quedado en el fondo de un espejo y me enseñó a celebrar el i de mayo, es... parte (medular) de mí8.

La realidad se abre paso a través de la ficción y viceversa:

Un dato más de ese juego onomástico que redunda en cómo la vida y las ficciones están unidas por el correspondiente cordón umbilical: mi bisabuelo era

\footnotetext{
7 Cfr. "La madre que llevó un sonajero a su fusilamiento", El País, I0-5-2019: https://elpais. com/elpais/2019/05/07/ciencia/1557240719_368278.html

${ }^{8}$ Marta Sanz: Parte de mí (202Ib: 2I). La eficacia moral del texto descansa en esa media distancia entre ficción y realidad y entre la verdadera autora y las narradoras intradiegéticas:

Aquí se recrean muy libremente los sucesos acaecidos en torno a la fosa de los Milagros (Burgos). No obstante, los personajes de pequeñas mujeres rojas nacen por completo de mi imaginación, y en ese sentido cualquier parecido con la realidad es mera coincidencia. En esta novela de nuevo, como en casi todas, se mezclan hechos reales y ficticios. Los primeros se presentan como simultáneos, aunque ni sucedieron al mismo tiempo ni se produjeron dentro de los límites de un mismo territorio. Son licencias poéticas de un texto que carece de pretensiones académicas o documentales. Espero que quienes lean estas páginas lo entiendan así (340).

Quien escribe estas páginas aparece, justo en este instante, fugazmente como Alfred Hitchcock (...) para constatar dos hechos: que quien escribe siempre es, centrípetamente personaje de una obra y que los personajes de una obra son las centrifugaciones enmascaradas que quien escribe (329).
} 
Benedicto Arranz, como Juana Arranz, como la madre de Martín, como Luz Arranz... Pero es que la mujer de Benedicto se llamaba Catalina San José. Con lo que las coincidencias se extienden a nombres y apellidos.

\section{$(\ldots)$}

Catalina, Catalina, que también era el nombre de una de mis mejores amigas en La lección de anatomía y el de la niña enmascarada bajo el pseudónimo fantaterrorífico de Daniela Astor... Qué madejas. Qué marañas9.

El coro ("el maestro y el destripaterrones, la mujer que no comulgaba, el palomo cojo y el masón y el chico que cantaba “La Internacional” con el puño en alto", I5I) reclama la condición de españoles para sus miembros: "También somos españoles”, “para nosotros, ser españoles era importante” (I5I). Y reclama un relato épico que acompañe la memoria de los huesos exhumados:

Incluso ya a estas alturas, sin que nadie se moleste, por favor, nos gustaría ser íntimos en nuestras lúbricas alcobas, pero también volvernos un poquito épicos. No sabemos si podría ser, por favor (I53).

Exigimos representaciones que sinteticen nuestra humanidad con nuestro heroísmo, porque lo uno no se entiende sin lo otro y nos desvirtúa $(332)^{\mathrm{IO}}$.

Marta Sanz vuelve a situar su cuerpo, esta vez con un derrame en el ojo, como centro de la escritura. En la novela nos encontramos con tres narradores (el coro, Paula Quiñones y Luz Arranz), pero al final de esta aparece la propia autora escribiendo la novela y diciendo "He sido yo" (330). Luz escribe por delegación de la verdadera autora de carne y hueso y ojo lacerado. Las voces que hablan desde el más allá de la fosa o las urnas han empapado su rabia en quien da la voz a Luz Arranz, quien escribe: "ella en los niños perdidos y las mujeres muertas y nosotros y nosotras en ella" (337). El cuerpo y el ojo enfermo de la autora obra como garantía del pacto firme del texto -y de la memoria que reconstruye el texto- con la realidad y la verdad. El cuerpo y los cuerpos -cojos, mutilados, tuertos, descoyuntados, putrefactos- representan

\footnotetext{
9 Son palabras de Marta Sanz en dos correos electrónicos sobre este texto con fecha 2I y 22 de junio de 202I.

1o El capítulo "Asesinos que ganan (lea despacio)", de donde proceden los entrecomillados, ha sido publicado por la autora de manera exenta bajo el título "Españoles" en Antonio Gallego, Roberto Martínez y otros (20I9), Negras\&Rojas/Noires\&Rouges. Le Noyau\&Ministerio de Justicia, pp. Io6-Iog.
} 
la apuesta de esta novela por una memoria histórica que se hace presente y sostiene una relación clara y unívoca con el pasado, el cual se recupera y actualiza de manera cierta y con un significado indubitable desde el propio título: "El puño se me levanta solo: estamos en nuestro derecho" (332). La novela se erige en un monumento de la memoria democrática: "estos folios son también un monolito" (333). La novela es arte figurativo y abstracto a la vez. No va a ser fácil disparar ni ultrajar a estos personajes como ocurrió con las esculturas de El Mirador de la Memoria.

El género negro es un contenedor útil para los fines militantes de la narradora y lo es porque para Sanz lo negro está al servicio del relato de la violencia:

Las narraciones negro-criminales durante sus décadas más gloriosas funcionaron como líquido de revelado fotográfico de la violencia del sistema ${ }^{\text {II }}$.

En un texto titulado "El negro es rosa y el rosa es negro", donde reflexiona sobre las fronteras de la novela negra y sobre cómo discernir la novela negra de consumo de la otra, deja Marta Sanz una declaración poética radical aplicable a esta novela que comentamos: el género negro se caracteriza por "su forma de construir el paisaje y, de paso, la soledad. Negro profundo y aleve. Negro" ${ }^{\text {I2 }}$.

No cabe duda de que lo negro solidifica, se ontologiza, en esta novela en torno a la soledad de la figura de Paula, la mujer que no supo si fue amada por su exmarido Zarco ni por ese amante-asesino hijo y heredero de los Beato con quien se estuvo acostando durante sus primeros días como voluntaria en Azafrán. Negra soledad.

El cuerpo de Paula, golpeado y maltratado hasta morir, el cuerpo de Paula Quiñones, pone al día las convenciones del género policial. La autora renuncia expresamente al detallismo forense de la novela de crímenes y de los relatos televisivos de consumo, en los que el lecto-espectador no se enfrenta a lo negro sino al "relato de lo negro", a las convenciones del género. Sin embargo, la suerte del cuerpo de Paula, explicada de manera metonímica con la descripción del aparato para manipulación de reses utilizado como potro de tortura (con la descripción del artefacto es suficiente; se repite como jaculatoria hasta quince veces entre las páginas 285-290), es una opción estratégica por parte de

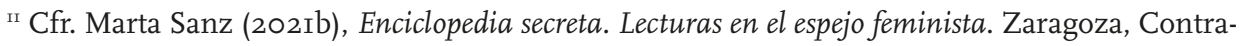
seña (en prensa), p. I9 del original.

${ }^{12}$ Ídem, p. I6.
} 
Sanz ${ }^{13}$. La descripción del asesinato de Paula desplaza un importante número de páginas en el tercer y último de los tres grandes bloques narrativos de que consta la novela. El tercero y último en lo que a la disposición temporal de la trama se refiere y en lo que afecta a la desestructurada linealidad de la fábula en planteamiento, nudo y desenlace. El desenlace es el crimen, anunciado desde el principio y la perpetuación de la estirpe de los criminales. El nudo de la trama, la parte central, está ocupado por el relato de los crímenes de la Guerra Civil perpetrados como consecuencia de la delación y la codicia del abuelo Jesús, bloque narrativo anterior cronológicamente a la llegada de Paula al pueblo, que se nos relata en primer lugar. El cuerpo torturado de Paula convierte el relato policial en un relato con contenido histórico. Ese cuerpo del delito es un sumatorio de la violencia del pasado y la violencia del presente: de la lucha y violencia históricas. Ulrich Winter ha señalado la importancia del cuerpo del investigador y del corpus delicti en el relato neopolicial. El cuerpo es:

El lugar donde se produce el "secreto encuentro" benjaminiano entre pasado y presente. No se trata de que los cuerpos implicados en el crimen representen la violencia en cuestión, sino de que encarnan la carga presenciadora del pasado, de que se transforman de testimonio en testigo ${ }^{\mathrm{I}}$.

El cuerpo de Paula es el espacio en que se reviven los crímenes del pasado. Los herederos del mismo que llevó a la fosa al maestro, al palomo cojo, etc., renuevan la condición criminal y codiciosa de su estirpe asesinando a Paula. Hay una analogía por contigüidad entre los muertos de la fosa y Paula: contigüidad del espacio físico, pues Paula está en el jardín del hotel de Azafrán y en el subsuelo del jardín yacen los cadáveres de la fosa común; y contigüidad por consanguinidad de los perpetradores pues los hijos y nietos reproducen la historia de los padres y abuelos. La analogía entre las víctimas de la guerra, las pequeñas mujeres rojas y Paula, la establece con nitidez pedagógica el texto al comienzo de la parte tercera, cuando se advierte al lector del desenlace inevitable, de la muerte de la protagonista:

\footnotetext{
${ }^{13}$ El cuerpo y el propio cuerpo de la autora como garantes de la escritura y del compromiso vital autobiográfico son un componente estético e ideológico recurrente en la escritura de Sanz: Lección de anatomía, Clavícula, Parte de mí. Véase Concepción Martín Huertas (2020) y el monográfico coordinado por C. Somolinos (2018).

I4 Ulrich Winter (20I7: 53) ofrece esta interpretación de la violencia ejercida sobre el corpus delicti en las novelas policiacas.
} 
La sangre de Paula, velocísima y grafitera, ha cubierto las flores como si saliese de un espray. Ella se cae redonda. Con la oreja en tierra, como la Tortolica hace tanto tiempo, comienza a escuchar las canciones de Nicolás, las nanas de Catalina y la lengua de trapo de Dickie Johnson. Pequeña encuentra a pequeña. Pequeñas todas. Paula no sabe por qué la van a matar, pero sin engañifas de trilero van a matarla $(227)^{15}$.

Marta Sanz, al comentar el libro de Eva-María Liffner (Goteburgo, I957), Hallazgo de un cadáver (Imago), enunciaba algunas peculiaridades del género negro de la autora sueca que tienen que ver con la función del cuerpo y el cadáver de Paula, con la insistencia en la descomposición de los cuerpos amontonados en la fosa y su transformación en las siniestras rosas "vestido español” (2II) del haunted garden de los Beato:

La escritura de Liffner crea la ilusión de que los estratos de la Historia se permeabilizan de modo que, en un giro paradójico, la Historia importa mucho porque no importa nada, y esa permeabilidad o ese pentimento pictórico anulan toda cronología en la misma medida en que hacen trascendente el pasado. Es como si no importase el orden en los acontecimientos, sino el peso específico de las acciones, individuales y colectivas, heroicas y repugnantes, interactuando entre sí en una concepción del tiempo donde todo es residuo y memoria viva. Cadáveres que aparecen en los pantanos, incorruptos cadáveres de mujeres congeladas. El cuerpo es un territorio donde se marcan las señales de la tragedia: en las descripciones lírico-forenses de Eva-Marie Liffner se equilibran deslumbramiento y morbidez. Los bellos cuerpos difuntos son epifanías del horror. Paisajes arañados por el alambre de espino de la guerra ${ }^{16}$.

Residuo y memoria viva es lo que son los cadáveres de los fusilados y hacinados en la fosa cuyas voces escuchamos como telón de fondo, límite y horizonte del texto novelesco.

\footnotetext{
Is Aunque el coro al que me vengo refiriendo está compuesto por diversas voces (el maestro, el brigadista, la madre) el texto insiste en dar voz a los más frágiles: "los niños perdidos y las mujeres muertas" (I3). Los niños perdidos están representados por la Tortolica, la niña huérfana de madre, hija de Tomé Melgar, que presencia horrorizada los fusilamientos y los enterramientos en el entorno de la casilla en la que vive. La niña que acabará trastornada, pero cuya sangre se fundirá con la de los Beato, acercaba su oreja a la fosa por si alguien pedía socorro. La fosa está oculta desde el 36 justo debajo de donde cae Paula Quiñones golpeada por la misma mano monstruosa del 36 . La suerte de los niños, víctimas en segundo grado y herederos de la violencia del 36, se trata también en la novela Los ojos cerrados (202I) de Edurne Portela. La fragilidad es signo de los tiempos.

${ }^{16}$ Enciclopedia secreta, en prensa (p. 225 del original).
} 
Mientras perdure una sola partícula de lo que fuimos, incluso desde el estado de ceniza o transformados en celuloide seguiremos hablando. Así ocurrirá, prometemos rubricarles una garantía [...] porque el gran problema -o la gran solución, who knows (...) es que la carne nunca muere. Vayan tomando nota. (...) No desaparecemos para siempre jamás cuando, supuestamente, se hace justicia y cada oveja está por fin con su pareja y comemos perdices y vivimos felices (I97).

La idea del mal y la explosión de la novela negra hacia los géneros fantasmagóricos y de terror que se produce en pequeñas mujeres rojas tiene su origen en este "secreto encuentro" del pasado con el presente y en la perpetuación del pasado. No acaba de triunfar la justicia tras la reconstrucción de los crímenes. Muy al contrario, se narra la supervivencia y perpetuación de los perpetradores que trabajan conjuntamente por la continuidad de su estirpe.

\section{Jesús Beato (1912-2015): el delator codicioso y su estirpe}

En los últimos años los estudios de memoria histórica han pasado a interesarse por la figura del victimario o del perpetrador al amparo del trabajo filosófico de Hannah Arendt sobre la figura del nazi Adolf Eichmann que la conmovió para conceptualizar la banalidad del mal. El carácter especulativo que adquiere el estudio de la figura de los victimarios desde este punto de vista en que los actos criminales no pueden explicarse de una manera racional convoca a la literatura como un terreno adecuado para la reflexión y la experimentación sobre la condición de los asesinos y la naturaleza de sus actos ${ }^{17}$.

La novela de Marta Sanz plantea una mise en abîme en la perpetuación del mal que se instala en la idea de la familia y la herencia -genética y económica-. El primer retrato que tenemos del perpetrador es un retrato de familia: la familia de los Beato celebra en un mediodía asfixiante el centésimo cumpleaños de Jesús Beato, que es el primer victimario, el fundador de la dinastía. El apellido que ha elegido Marta Sanz para esta familia es, obviamente, un nombre parlante. Constituye una ironía sobre la casi santidad o beatitud de una familia de asesinos y de manera contextual el apellido ironiza sobre

\footnotetext{
17 Pablo Sánchez León (20I8) argumenta sobre la legitimidad de la literatura de ficción para experimentar con los problemas morales que plantean los perpetradores. Se sigue en este apartado sus avances en el establecimiento de una tipología de victimarios. Desde un punto de vista estrictamente histórico, Aguilar Fernández y Payne (20I8) recapitulan sobre los escasos testimonios de victimarios de la guerra de que se disponen.
} 
los valores e hipocresías que constituyeron el fundamento de la sociabilidad durante el nacional catolicismo. Estos valores parecen perdurar en 2012 en el pueblo de Azafrán-Azufrón cuyos habitantes callan a propósito de la condición del abuelito Jesús.

Desde el punto de vista de los estudios sobre el "giro victimario" Jesús Beato pertenece al tipo de los que no sienten ninguna necesidad de confesar, ni sienten arrepentimiento. Entre los Beato solo siente necesidad de hacer aflorar el pasado criminal familiar Samuel. Samuel aporta la prueba documental que llevará al asesinato de Paula y al descubrimiento de la fosa: el cuaderno donde el abuelo Jesús anotaba tanto el objeto de su codicia, las pequeñas o grandes posesiones de sus víctimas futuras, como el anecdotario biográfico que los llevaría a la fosa común ocultada. Samuel, que quería confesar en alguna medida, acaba asesinado por las monstruosas mujeres de la familia y por su hermano como un galgo que ya no corre lo suficiente, colgado de un árbol y con los pies arañando el suelo.

No hay confesión del victimario, antes bien, la novela pone de manifiesto todo un contexto social -empezando por los nombres de las calles, que conservan la nomenclatura franquista- en el que la identidad del victimario Jesús Beato es reconocida y está segura y vinculada a valores "propios del contexto de perpetración (...) que sigue constituyendo su comunidad referencial” (Sánchez León, 20ı8: I76). Jesús Beato morirá tranquilamente y bien cuidado por la sobrina nieta de una de sus víctimas-en una residencia en 2015. Solo la comisión de nuevos crímenes -el de Paula y el de Samuel- llevará a la cárcel a las mujeres monstruosas, Analía y María, y a Paquita y Luis. Quedarán libres como herederos materiales y morales de la dinastía el hijo pequeño de Jesús Beato, el demoníaco Fausto, y el nuevo criminal, hijo de Samuel y Analía, David Beato.

Jesús Beato no es un victimario ejecutor, no es un verdugo, es un delator. Por su condición de barbero a la altura de 1936 llevaba varios años recorriendo los pueblos del entorno de Azafrán y anotando cuanto observaba en su cuaderno. Allí anotó que el maestro que yace en la fosa mostraba en el bar un codiciable reloj. El mal encuentra un anclaje racional en la codicia. La codicia es lo que mueve al abuelo Jesús a anotar en su cuaderno todo lo que ve y quiere para sí: pinares, tierras fértiles, casas o el reloj del maestro. También en el contenido del cuaderno del abuelito Jesús, como en la personalidad de los fusilados y en particular la de Catalina, la autora acerca su texto a la verdad histórica: la inanidad de las acusaciones por las que muchos fueron delatados 
y fusilados por falangistas y tropas rebeldes ${ }^{18}$. En las páginas I32-I33 se encuentra una descripción de los contenidos del cuaderno del delator incluso con un algún comentario de estilo.

El joven Jesús había tomado nota de certezas documentales sobre sus delatados que podían serle útiles para apoyar sus denuncias: tesorero de la casa del pueblo; promotor de un intento de huelga; blasfemo, anticlerical, sus hijos se llaman Boreal y Harmonía; maestro y amigo de comunistas; mujer hosca que levanta el puño y mira sañudamente; dueño de tierras fértiles junto a la laguna Madriguera -esto lo ponía en mayúsculas porque era un dato importante para él, quizá no tanto para los que hacían las sacas de fusilados-, masón; esta no comulga ni reza; destripaterrones que se folla a la hija del boticario.

Más detalles sobre el cuaderno de Beato:

Jesús Beato siempre traía apuntados en su cuaderno los motivos de condenación: morder la hostia que era el cuerpo de Cristo, conspirar, promover reuniones clandestinas, ser un fornicador o una puta, dar dinero a los rojos, pronunciar un discurso, esconder una pistola, ocultar víveres. Después de cada saca y cada fusilamiento anotaba los beneficios: otro pinar, una tienda, un solar vacío, una casona. Jesús Beato acompañaba a los ejecutores, que después se lavaban las manos y se refrescaban la cara en la caseta del peón (202).

La bibliografía sobre el holocausto nazi está dirigiendo el interés hacia los hijos y herederos de los grandes victimarios. Philippe Sands en su biografía del nazi Otto Wächter, responsable de la organización del exterminio de judíos en Polonia, consigue poner de manifiesto no solo que "el genocidio era el negocio oficial" (Sands, 202I: 4I3). Sino que, además, deja patente cómo el usufructo de la rapiña impregna a las familias de los victimarios: las esposas y luego también los hijos y nietos. La refinada y emprendedora esposa de Wächter, Charlotte, se especializó en el expolio de obras de arte de los museos polacos. De esta rapiña vivirán tras la guerra y estas obras de arte serán la heredad de los hijos de los nazis, algunos de los cuales se resisten en la actualidad a

${ }^{18}$ Cfr. los testimonios recogidos por Montserrat Armengou y Ricard Belis (2004), Las fosas del silencio. ¿Hay un holocausto español? Para la historicidad de los motivos de delación de esta novela puede verse también el capítulo I del documental del mismo título, minuto I9-20. El reloj como objeto codiciado que pasaba de la víctima al victimario está recogido también en Aguilar \& Payne (20I8). 
restituir como proceda estos bienes ${ }^{19}$. La maligna red de intereses y los vínculos de sangre entre los victimarios y sus hijos constituyen un inextricable laberinto de culpas. Philippe Sands reconstruye las continuidades, interconexiones y consanguinidades de los hijos de los nazis amigos o relacionados con los Wächter, favorecidas por el anticomunismo de la Guerra Fría ${ }^{20}$.

La novela de Marta Sanz señala en esta misma dirección desde el terreno de la ficción verosímil: los bienes obtenidos mediante el asesinato se heredan y con ellos la condición de victimario. Se heredan el mal y el rechazo al establecimiento de una relación estable y fidedigna con la verdad histórica. Los lazos de sangre entre la menoscabada estirpe de Tomé Melgar y la del barbero Beato, bien amarrados por el abuelo Jesús, hacen irrespirable y temible la herencia conjunta de la brutalidad, la culpa y las posesiones. El mal se perpetúa bajo la especie de codicia. La trama de Sanz hace, además, que los herederos se conviertan a su vez en asesinos cuando ven amenazados la conservación y el aumento del patrimonio logrado con la delación y el crimen por el abuelo Jesús.

\subsection{Los estigmas de la estirpe}

La entrada de Paula en el para ella nauseabundo salón familiar de los Beato permite ver la siguiente escena presidida por la sonrisa beatífica del centenario abuelito Jesús, el victimario:

Era como si, en el momento en que la intrusa había aparecido, al viejo le estuvieran haciendo una ofrenda de oro, incienso y mirra. En el portal de Belén

\footnotetext{
I9 "La afición al arte de Charlotte, así como su instinto de posesión, se transmitirían a las futuras generaciones. Cuando les llegó el momento de casarse, ella ofreció como regalo de boda a cada uno de sus seis hijos alguno de los objetos que había adquirido (...) La representación de san Jorge matando al dragón todavía se hallaba en posesión de un miembro de su familia que no tenía la menor intención de separarse de ella. (...) posiblemente expoliada al museo de la catedral de Cracovia. (...) Me explicó que sus propios actos, al devolver diversos objetos, habían suscitado reacciones muy negativas por parte de algunos miembros de la familia. Se decía que su cuñada estaba "completamente abatida" por sus acciones, y una de sus hermanas le había dicho que era un Judas, que había traicionado a la familia, mientras otra se había sumido en una "profunda depresión" (Sands, 202I: 249).

${ }^{20}$ Véase el capítulo 46 de Ruta de escape, en particular p. 385. Sánchez León (2018) comenta como obra de ficción relevante de este giro victimario en Europa Las benévolas de Jonathan Littell (2007).
} 
el niño Jesús había envejecido aceleradamente, pero quedaba el tibio hedor a bueyes y excrementos de mula (p. 36).

Paula, según cuenta Luz Arranz, se fijó ya en el extraño aire de familia de los Beato:

Todos, incluso los que tendrían un parentesco político o lejano con el abuelo Jesús, compartían un aire familiar. Una telilla superpuesta a los rostros y al bulto del cuerpo de cada uno los hacía semejantes. Como si un animal los hubiese semidigerido y regurgitado para comérselos luego. Los rasgos, difuminados o corroídos por los jugos estomacales, correspondían a especímenes de gente pálida, de pestañas casi albinas y mejillas redondas, especímenes rosáceos sin estridencias, manada sin filos, ni pómulos ni uñas largas (37).

La narradora dota de otros rasgos malignos y monstruosos a la estirpe: los pies "monstruosamente grandes" (36) del abuelito, que también presenta al menos una de las dos primas, Analía o María Melgar. Las primas Melgar heredaron "las gigantescas manos" (204) con las que su abuelo Tomé Melgar arrojó un hijo muerto a la piara y cavó la fosa oculta bajo la casa y hotel de los Beato. Los ojos de ratón de David (hijo de Samuel Beato y Analía Melgar) también son otra señal de malignidad: las pupilas "siempre rojizas o del color del yodo” (228), están entre lo broncíneo y el rojo de los ratones. Sus pestañas son lechosas y como inexistentes.

La manera en que es deglutida Paula por la vaina-bolsa en la que la conducen al cadalso, convertida ya en víctima o semivíctima se asocia con ese aspecto y marca de los Beato, aspecto de estar como recubiertos por cierta viscosidad:

En su semiinconsciencia Paula no sabe si son dos manos o cuatro las que la manipulan y van alzándola para incrustarla en su vaina de guisante. (...) De los pies a la cabeza, su cuerpo es levantado por secciones mientras la tela se la va comiendo como las serpientes degluten a los ratoncillos vivos. Lo que queda parece a la crisálida de un gusano, Pero no es ni lo uno ni lo otro, ni crisálida, ni vaina, ni serpiente: es una mujer metida dentro de un saco (228).

La exaltación del trabajo, lo muy trabajador que era el abuelo Jesús y el trabajo compulsivo de Analía (53) y de María configuran la etopeya familiar: se matan a trabajar, exaltan el trabajo incesante en un afán impúdico por creerse y hacer creer que su riqueza viene de su trabajo. "Nadie puede trabajar tanto como para hacerse tan rico” (80). La novela cuestiona el origen de la riqueza 
de los ricos y de la pobreza de los pobres, al paso que afirma una y otra vez que no todos perdieron lo mismo en la Guerra Civil.

\subsection{Modos de representación del mal}

Como la gran creación literaria que es pequeñas mujeres rojas se estructura planteando una reflexión -teoría y práctica- sobre los modos de representación, en concreto, la representación del mal y de la violencia. La claridad de ideas de la novela, la convicción de que hay buenos y malos, de que unas familias son mejores que otras, facilita la oposición básica de la novela: las pequeñas mujeres rojas (Paula, la Tortolica, Luz Arranz y la verdadera autora) frente a las mujeres monstruosas (Analía y María Melgar). Esta últimas se representan con técnicas de cuento maravilloso de terror ${ }^{21}$. Las cosas terribles de Azufrón se relatan por aproximación a cuentos tradicionales o a conocidos relatos de terror, algunos dilectos de la autora Marta Sanz: la historia de la loca del desván, la Tortolica, recoge la inclinación de la autora hacia la película Rebeca (i940) dirigida por Alfred Hitchcock. El comienzo de la parte titulada "Poltergeist" (como la película de I982 producida por Spielberg que habla de los fantasmas del subsuelo y de cómo regresan al mundo de los vivos) es el de un cuento infantil: "Había una vez un peón caminero que tenía dos hijos" (59). Toda la parte de la persecución de Paula a través del bosque se proyecta sobre la versión cinematográfica de Alicia en el país de las maravillas de Tim Burton y contiene una parodia de las clásicas fábulas "del tío Walt" (336) con animalitos y niñas en el bosque.

Es en la parte final de la novela, "Estabulación (Tratado para pieles delicadas)", donde la novela se hace más explícitamente metaliteraria. La cita de la entrevista de Marguerite Duras a Francis Bacon en la que Bacon afirma que el tema de una obra de arte siempre es el mismo y que lo específico es la imaginación técnica nos da la clave del esfuerzo y consciencia formal de la autora en toda la novela y en el capítulo "Estabulación".

\footnotetext{
${ }^{21}$ Véase la aparición fantástica de María Melgar (pp. Io8-II2) en la oficina donde trabajan las voluntarias Rosa y Paula: "había iluminado la oficina con una luz azul y el hedor de un alimento mal descongelado lo impregnaba todo" (го8). María Melgar amenaza a las voluntarias: "Nosotros hemos pasado ya mucho, mucho, para que nadie venga aquí a escarbarnos la tierra, que es nuestra tierra, ¿me oís? Nuestra” (I09). Crecían sus brazos mientras hablaba como en un dibujo de cuento... (Cfr. IIo). "Hasta ahí llegó la eficacia fantasmagórica” (II2).
} 
La representación del mal y su hermano, el crimen violento, es una cuestión técnica: de representación de la realidad. Marta Sanz en esta novela-que es una novela realista, de significado histórico claro y conciso, incluso una novela de tesis y de propaganda- opta por resignificar el relato de los crímenes de la Guerra Civil y el asesinato de Paula a través de referencias al cine de fantasías terroríficas ${ }^{22}$. En lo que se refiere a la condición de los perpetradores hay tres referencias cinematográficas que operan como estructurantes de esa imaginación técnica o revelación o mancha o atmósfera que llevan a Sanz a hacer perceptible el mal. Por orden de aparición: La corona negra (I95I), Svengali (I93I) El barbero diabólico (The Demon Barber of Fleet Street, 2007) de Tim Burton $^{23}$.

Las tres son historias en las que el móvil de la conducta criminal o, decididamente, del asesinato es el dinero. Las dos últimas referencian la figura de Jesús Beato con lo diabólico ${ }^{24}$. Los ojos y la mirada de Svengali en la película de Archie Mayo son una cuestión técnica. La telilla, polvo, baba que parece recubrir la consanguinidad y cohabitación de los Beato tiene que ver con la mirada de Svengali, con las técnicas todavía rudas del cine fantástico y de terror. Los ojos broncíneos, rojizos, anaranjados, de ratón de David Beato tienen también que ver con Svengali y con esa forma primitiva de contar de las

\footnotetext{
${ }^{22}$ Las marcas de la literatura de género (negro o fantástico) están al servicio de la producción de un significado histórico-realista. Sobre el realismo en Marta Sanz Cfr. Marta Simó (20I8): "El realismo literario de Marta Sanz se fundamenta en una lucha contra la idealización de la realidad, así como en la defensa de la dignidad ontológica de la novela, entendida como objeto cultural y como instrumento de denuncia social". Sobre la utilización del género negro por parte de Marta Sanz véase Francisco Álamo Felices (2017) y C. Varón González (2020).

${ }^{23}$ Tim Burton es objeto de imitación y homenaje en esta novela. Nada menos que las voces del "coro polifónico" y "de los niños perdidos y las mujeres muertas" agradecen a Tim Burton la película La novia cadáver. Este agradecimiento tiene que ver con el reconocimiento del linaje de las licuefacciones, putrefacciones y evolución de los cadáveres de la fosa en los que se demora la autora, a veces con eficaz lirismo: "También agradecimos a Tim Burton La novia cadáver. Lloramos mucho cuando nos trajeron una copia pirata, y deseamos que la chica azul y vaporosa nos acompañase en nuestro lecho de tierra (...) El maestro, siempre al quite, destacó la relación intertextual de la película con La muerta enamorada de Téophile Gautier" (I67-I68). Marta Sanz sabe de la tradición literaria de los barberos y también de la versión del barbero Sweeney Todd dirigida por George King.

${ }^{24}$ Svengali, película de I93I basada en la novela de George du Maurier, Trilby, de I894. "Nos encanta Svengali, y siempre, siempre que podemos, lo sacamos a colación" (2I4). Todo son referencias demoníacas en esa página, incluido el tío "Fausto" que corta las rosas del jardín, en el momento en que Jesús Beato recoge en su casa con afecto a Julia, la Tortolica. La evocación de la entrada de Julia enloquecida a los espacios de la casilla-fosa-hotel y el engendro-engendramiento de David da miedo y náusea al lector. Todo, la obra demoníaca de Jesús Beato.
} 
primeras novelas realistas y del primer cine en blanco y negro, que se basaba en las fisiognomías: ese rudimento de psicología en que se apoyaron tantos grandes relatos decimonónicos (v. gr. Los Miserables o El Conde de Montecristo). La historia de Sweeney Todd subraya una vez más la diabólica codicia criminal del barbero Jesús Beato y subraya la rara comunión -canibalismo, necrofagia- en la que se funda la unión de los descendientes de Beato y los de Tomé Melgar. Tomé Melgar arrojó a los cerdos el engendro que al nacer había matado a su esposa Arminda y después desolló esos mismos cerdos para alimentarse él y alimentar a su prole: círculo gástrico infernal.

La corona negra (I95I), película de género negro llena de referencias mágicas, también funciona como núcleo imaginativo y fantasioso-fantástico en torno al que gravitan bastantes páginas de la novela y la idea fundamental de la justa memoria y la amnesia criminal. La corona negra presagia la muerte inminente y consiste, como en la película, en el círculo que forman los buitres al sobrevolar un terreno, en este caso, la fosa oculta bajo la casa de los Beato desde 1937. Las voces nos informan: "Desde aquellos días los buitres cogieron la costumbre. Nos sobrevuelan un año detrás de otro" (I99). Durante la tarde que precede a la noche en que muere Paula sobrevuela el jardín la corona fatídica. Por otra parte, la película de Saslavsky relata la amnesia que sufre una mujer que ha asesinado a su marido para hacerse con sus diamantes. Primero la amnesia es fruto del shock tras el acto violento. Luego la película muestra cómo la mujer va recordando y se ampara en una amnesia ya fingida e interesada, económicamente interesada. La poderosa fotografía de esta película aporta a la relación simbiótica entre el relato fílmico y el narrativo la visualización del imborrable recuerdo del crimen y del clamor de los huesos de los muertos, que alcanzan fantasmagóricamente la superficie de la tierra desolada que los alberga ${ }^{25}$.

La imaginación técnica que sustenta la novela de Sanz, así como el traslado verbal de formas de representación del cine de terror y de las películas de animación del mismo sesgo, habrán de ser objeto de otros estudios monográficos. Quede consignada con estas referencias la explosión de la fábula negra hacia lo fantástico -demoníaco, monstruoso- como estrategia discursiva básica en pequeñas mujeres rojas para volver a representar y resignificar el impacto moral que viene provocando en la España de los últimos lustros la apertura

\footnotetext{
${ }^{25}$ La película es española y fue dirigida por el argentino Luis Saslavsky. El argumento procede de Jean Cocteau, que reelaboró La Venus de Ille de P. Merimée. Los diálogos en español, de Miguel Mihura.
} 
de las fosas comunes de la Guerra Civil y los conflictos en torno a las exhumaciones $^{26}$. Es un síntoma reciente en la narrativa de mujeres el resurgimiento de lo fantástico, incluso en obras en que se quiere convocar un sentido histórico-realista para la fábula ${ }^{27}$. Merece un comentario la relación hipotextual de esta novela con Alicia en el país de las maravillas (y la versión de Tim Burton para Disney). "Que le corten la cabeza”, la reconocible frase que pronuncia la reina de corazones, forma parte del bordoneo premonitorio de la anunciada muerte de Paula y se repite significativamente al comienzo de la novela y al comienzo del suplicio de nuestra detectivesca voluntaria. "Las repeticiones, al fin, son evocación de la muerte”. Como la referencia salmódica al coro de los niños perdidos, que es el coro de los niños muertos, y que vive en el subsuelo como los niños perdidos de Peter Pan o, españolizado, "Pedro Pan" (328). La operatividad del texto de Lewis Carroll en la poética de Marta Sanz, y en su poética de la lectura en particular, así como la visión irónica de los modos de representación de los cuentos tradicionales ofrecidos al consumo global por esa misma factoría norteamericana en su época clásica, anteriores a la mencionada de Tim Burton, son cuestiones que atraviesan la obra de ficción y la escritura ensayística de Sanz. El acompañamiento e indicaciones de los animalitos del bosque a las jóvenes pequeñas y paulinas en peligro, que provienen de La bella durmiente, son un mentís a la mala educación sentimental de las mujeres, enmascaran el verdadero peligro y la crueldad que las va a victimizar. Estos animalitos Disney, que son referencia emblemática de la urgencia de la deconstrucción feminista de estos relatos tradicionales, acompañan a Paula en su inútil intento de escapar por el bosque, por "el pinar más oscuro" (275-283), y convierten la escena en una parodia de la convencional representación folclórica de los peligros que arrostran las mujeres y de los príncipes y cazadores que acuden a salvarlas.

\footnotetext{
${ }^{26}$ El contexto planteado por Francisco Ferrandis (2008) queda bien recogido en pequeñas mujeres rojas tanto en las cuestiones antropológicas sobre cómo acompañar y solemnizar las exhumaciones como en las reacciones contrarias a las exhumaciones en el medio rural.

${ }^{27}$ pequeñas mujeres rojas se publicó casi simultáneamente y en la misma colección que Malasangre de Michelle Roche (Anagrama, 2020), una novela histórica sobre Venezuela y una novela de vampiros. Sobre el auge de la literatura no mimética y su cultivo por parte de las mujeres véanse los recientes panoramas (20I9): Ricardo Ruiz Garzón, Insólitas. Narradoras de lo fantástico en Latinoamérica y España (Páginas de Espuma); N. Álvarez Méndez y A. Bello Verano editan una panorámica sobre literatura fantástica (gótica, distópica, etc.) en Realidades Fracturadas. Estéticas de lo insólito en lengua española (1980-2018) (Visor); Patricia García, Teresa López-Pellisa y Raquel Velázquez han coordinado Expresiones del horror en la ficción hispánica (Aluvión).
} 
Queden aquí estas líneas sobre los modos de representación del mal y sirvan para señalar la envergadura literaria de pequeñas mujeres rojas, la relevancia de su compromiso con la construcción de la memoria democrática en España y su conexión con el giro victimario en la literatura y en los estudios histórico-antropológicos sobre el pasado violento en Europa y España.

\section{Bibliografía}

Aguilar Fernández, Paloma \& Ferrandiz, F. 20I6. Memory, media and spectacle: Interviú's portrayal of Civil War exhumations in the early years of Spanish democracy. Journal of Spanish Cultural Studies I7 (I): I-25.

Aguilar Fernández, Paloma \& Payne, Leigh A. 20I8. El resurgir del pasado en España. Fosas de víctimas $y$ confesiones de verdugos. Madrid: Taurus.

Álamo Felices, Francisco. 20I7. La subversión de la novela criminal como propuesta ideológica alternativa: la reconversión del subgénero negro en "Black, black, black" (20I0) y "Un buen detective no se casa jamás" (20I2), de Marta Sanz. Pasavento: revista de estudios hispánicos 5(2): 357-38I.

Ferrándiz, Francisco. 2008. Cries and Whispers exhuming and narrating defeat in Spain today. Journal of Spanish Cultural Studies 9:2: I77-I92. doi: I0.1080/14636200802283704

Ferrándiz, Francisco. 20I4. El pasado bajo tierra. Exhumaciones contemporáneas de la Guerra Civil. Barcelona: Anthropos.

Gatti, Gabriel (coord.). 20I4. Kamchatka. Dossier: Las víctimas de aquí. Singularidades y tradiciones estéticas de un personaje en crecimiento, núm. 4.

Ingenschay, Dieter \& Janett Reintädler. 20II. Culturas del después: acercamientos a la producción literaria y cultural en Europa e Hispanoamérica. En Reinstädler, Janett (ed.) Escribir después de la dictadura. La producción literaria y cultural en las posdictaduras de Europa e Hispanoamérica. Madrid/Frankfurt: Iberoamericana/Verbuert, 9-2I.

Littell, Jonathan. [2006] 2007. Las benévolas. Barcelona: RBA.

Martín Huertas, Concepción. 2020. "Digo carne": La repolitización del cuerpo femenino en la narrativa de Marta Sanz. Studia Romanica Posnaniensia 47(I): 67-80.

Matas Pons, Alex. 202I. El archivo visual y la memoria literaria de la Transición, dos instantáneas posfotográficas: Javier Cercas y Marta Sanz. Hispanic Review 89 (I): $25-43$.

Naval, María Ángeles. 20I9. Memoria de la Transición en la novela española de los 2000. En Peña Ardid, Carmen (ed.) Historia cultural de la Transición. Pensamiento crítico y ficciones en literatura, cine y televisión. Madrid: Catarata, 98-iI7.

Naval, María Ángeles. 202I. Pensar, leer, pensar (conjúguese en femenino plural). En Sanz, Marta Enciclopedia secreta. Lecturas en el espejo feminista. Zaragoza: Contraseña, en prensa. 
Ros Ferrer, Violeta. 20I4. Contar la transición, o cómo hablar de la china en el zapato. Entrevista a Marta Sanz. En Ros, Violeta (coord.) Contar la Transición: discursos e imaginarios del proceso de cambio político en España, Kamchatka 4: 257-263.

Ros Ferrer, Violeta. 2020. La memoria de los otros. Relatos y resignificaciones de la Transición en la novela actual. Madrid: Iberoamericana Verbuert.

Sánchez León, Pablo. 20I8. Esa tranquilidad terrible. La identidad del perpetrador en el "giro" victimario. Memoria y narración. Revista de estudios sobre el pasado conflictivo de sociedades y culturas contemporáneas I(2018): I67-I83.

Sands, Philippe. 202I. Ruta de escape. Barcelona: Anagrama.

Sanz, Marta. 2020. pequeñas mujeres rojas. Barcelona: Anagrama.

Sanz, Marta. 2021a. Parte de mí. Barcelona: Anagrama.

Sanz, Marta. 202Ib. Enciclopedia secreta. Lecturas en el espejo feminista. Zaragoza: Contraseña, en prensa.

Schönpflug, Daniel. 2020. El mundo en vilo. La ilusión tras la Gran Guerra. Madrid: Turner.

Simó-Comas, Marta. 20I8. La realidad y sus representaciones: una aproximación a la poética realista en la obra narrativa de Marta Sanz. En Somolinos Molina, C. (ed.) Escrituras del cuerpo: Marta Sanz. Olivar, i8(27): s. p.

Somolinos Molina, C. (ed.). 20I8. Olivar. Revista de cultura y literatura españolas. Monográfico: Escrituras del cuerpo. Marta Sanz I8(27), s. p.

Varón González, C. 2020. The long goodbye of Marca España: affect, politics and modernity in Marta Sanz's crime novels. Journal of Spanish Cultural Studies 2I(2) (April): 255-273.

Winter, Ulrich. 20I0. De la memoria recuperada a la memoria performativa. Hacia una nueva semántica cultural de la memoria histórica en España a comienzos del siglo xxi. En Docuficción. Enlaces entre ficción y no-ficción en la cultura española actual. Madrid: Iberoamericana-Vervuert.

Winter, Ulrich. 20I7. Corpus delicti. Justicia poética, justicia histórica. El giro forense y el materialismo en la novela negra posdictatorial (acerca de la serie Heredia de Ramón Díaz Eteróvic). Schnjmitz Sabine et al. Descubrir el cuerpo. Estudios sobre la corporalidad en el género negro en Chile, Argentina y México. Madrid: Iberoamerina Verbuert, 45-56.

Winter, Ulrich. 20I8. Memoria histórica e imaginación jurídica: políticas estéticas de la memoria, desde la justicia poética al forensic turn. Memoria y narración. Revista de estudios sobre el pasado conflictivo de sociedades y culturas contemporáneas I: I84-I97. 